\title{
РЕАКЦИЯ СОСНЫ ОБЫКНОВЕННОЙ НА НЕУМЕРЕННЫЕ ВЫБРОСЫ В АТМОСФЕРУ ЗАГРЯЗНЯЮЩИХ ВЕЩЕСТВ
}

\author{
Нина Даниловна Давыдова \\ Scopus Author ID: 7005229945, Research ID: J-3280-2018, SPIN-код: 5881-1541, Author ID :66796, \\ e-mail: davydova@irigs.irk.ru \\ Институт географии им. В. Б. Сочавы СО РАН, Иркутск, Россия
}

Проведены определение и анализ показателей геохимической среды обитания и состояния древесных пород деревьев растительных сообществ таежных геосистем, находящихся длительное время (более 50 лет) в зоне воздействия пылегазовых эмиссий одного из крупнейших в Сибири предприятий по производству алюминия. Среди анализируемых видов растений наиболее отзывчивой на изменение геохимических условий среды обитания оказалась сосна обыкновенная (Pinus silvestris L.), у которой меняются не только химический состав, но и морфологические характеристики. В многолетнем цикле поступления поллютантов реакция сосны обыкновенной хорошо диагностирует как периоды снижения их нагрузок, так и повышение, что особенно хорошо проявляется вблизи источника эмиссий. Достаточно чутко она реагирует также и на изменение химического состава вещества в пространстве. С удалением от завода по производству алюминия в хвое сосны появляются химические элементы, характерные для других источников загрязнения. В новых геохимических условиях обитания сосна проявляет резистентность. Выделена ассоциация элементов, которые она усиленно поглощает, и тех, поглощение которых подавлено. Использование сосны обыкновенной в качестве индикатора загрязнения наряду со снежным покровом позволяет выявлять приоритетные элементы-загрязнители и их источники, устанавливать и нормировать нагрузки поллютантов, вести независимый контроль над массой выбросов в атмосферу и разрабатывать рекомендации по их снижению.

Ключевы е слова : геосистема, геохимическая среда, сосна обыкновенная, химический состав, нагрузки поллютантов, листовая диагностика.

\section{RESPONSE OF SCOTS PINE TO INCREASED EMISSIONS OF POLLUTANTS INTO THE ATMOSPHERE}

\author{
Nina D. Davydova \\ Scopus Author ID: 7005229945, SPIN-код: 5881-1541, Author ID: 66796, Research ID: J-3280-2018 \\ e-mail: davydova@irigs.irk.ru \\ V.B. Sochava Institute of Geography SB RAS, Irkutsk, Russian Federation
}

In the study, the author determined and analyzed indicators of the geochemical habitat and the state of tree species of plant communities in taiga geosystems being exposed for a long period (more than 50 years) to dust and gas emissions of one of the largest aluminum production enterprises in Siberia. Among the plant species analyzed, Scots pine (Pinus silvestris L.) was found to be the most responsive to changes in the geochemical conditions of the habitat as it showed changes not only in its chemical but also in its morphological composition. In the long-term cycle of pollutant inflows, the reaction of Scots pine clearly indicates periods of both reduction and increase in the pollutant loads, which is especially well manifested near the source of emissions. It also reacts quite sensitively to changes in the chemical composition of a substance in space. With a distance away from the aluminum plant, pine needles were found to contain elements that are characteristic of other sources of pollution. In the new geochemical habitat conditions, the pine shows resistance. There were identified associations of elements that it intensely absorbs and those the absorption of which is suppressed. The use of Scots pine as a pollution indicator along with snow cover makes it possible to identify primary polluting agents and their sources, determine and normalize pollutant loads, conduct independent control over the mass of atmospheric emissions and develop recommendations for their reduction.

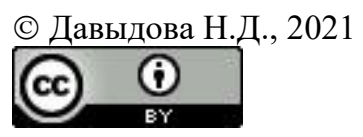


Ke y w ords : geosystem, geochemical environment, Scots pine, chemical composition, pollutant loads, leaf diagnostics.

\section{Введение}

В середине XX в. перед обществом остро встала проблема загрязнения природной среды. Возникло опасение распространения техногенных веществ на Земле, которые могут изменить геохимический фон на всех уровнях геосферы: локальном, региональном и глобальном [5; 9; 20; 22; 27]. Негативное воздействие эмиссий промышленных предприятий стало проявляться, прежде всего, на растительном покрове, вызвав тревогу в обществе, что послужило причиной активизации исследований в этом направлении $[8 ; 12 ; 13 ; 27 ; 36]$. Если проблема загрязнения природной среды сернистым газом в какой-то мере решена путем газификации и использования малосернистого бурого угля, то проблема загрязнения тяжелыми металлами [22; 26; 30; 32; 34], фторидами [8; 10; 25; 29; 33; 37], канцерогенами [31; 35] и другими вредными веществами еще остается.

В формировании биогенных природных систем и их стабилизации важную роль играет живое вещество как ведущий фактор. Кроме этого, биотические компоненты, которые чутко реагируют на изменения геохимических условий среды обитания, служат главным индикатором техногенной трансформации геосистем. Так, при сжигании на тепловых станциях (ТЭЦ) малосернистых бурых углей в составе зольных частиц преобладает окись кальция $(\mathrm{CaO})$, которая при взаимодействии с водой превращается в гидроокись $\left[\mathrm{Ca}(\mathrm{OH})_{2}\right]$, имеющую сильную щелочную реакцию $(\mathrm{pH}=11-12)$. При этом кислая реакция лесных почв заменяется щелочной, а кальций становится типоморфным (главным) элементом геохимической среды. Соответственно в растительных сообществах наблюдается структурная перестройка, где виды ацидофилы-кальцефобы замещаются базифилами-кальцефилами, а также видами широкой экологической амплитуды [4]. При воздействии газообразных веществ нарушаются процессы метаболизма растений или происходят их быстрое поражение и гибель $[1 ; 12 ; 15]$, что также обусловливает структурную перестройку сообществ. Подобные нарушения растительного покрова вследствие атмосферного загрязнения отмечаются на территории, прилегающей к БрАЗу, которые проявляются в его деградации с почти полной сменой состава и разрушением структуры, появлением низкорослых карликовых форм хвойных и лиственных пород деревьев, хлороза и некроза листьев, потерей возможности возобновления коренной растительности.

Было замечено, что вопреки сложившемуся мнению о неустойчивости сосны обыкновенной в подобных условиях $[8 ; 12 ; 13]$ отдельные ее особи выживают и относительно нормально развиваются. В то время как более устойчивые древесные породы (лиственница сибирская и ель сибирская) сохраняются лишь в карликовой форме под прикрытием травяно-кустарникового полога. При этом у сосны в разные годы отмечаются сгущения веток ствола в процессе роста за счет уменьшения междоузлий [11]. Указанные особенности поведения сосны вызвали необходимость изучения взаимосвязи между нагрузками поллютантов, интенсивностью их поглощения сосной обыкновенной и ее жизненном состоянии.

Цель исследования - выявить реакцию сосны обыкновенной на изменение геохимических условий среды обитания и оценить возможность ее использования в качестве индикатора атмосферного загрязнения.

\section{Материал и методы исследования}

Многолетнее (1996-2018 гг.) изучение трансформации компонентов таежных геосистем проведено на территории, подверженной воздействию пылегазовых эмиссий крупного предприятия цветной металлургии ОАО «РУСАЛ» - Братский алюминиевый завод (БрАЗ) и иных источников. Объект исследования - южно-таежные плоскогорные геосистемы Средней Сибири, находящиеся более 50 лет в зоне атмосферного загрязнения. Растительный покров смежной с заводом территории достаточно разнообразен. На фоне осиново-березовых и березово-осиновых травяно-зеленомошных вторичных лесных сообществ встречаются коренные горнотаежные темнохвойные кедрово-пихтовые (Pinus sibirica Du Tour., Abies sibirica Ledeb.) с участием ели (Picea obovata Ledeb.) кустарничковые (Rhodococcum vitisidaea L., Vaccinium myrtillus L.) мелкотравно-зеленомошные массивы лесов. По долине р. Вихорева и берегам Братского водохранилища распространены подтаежные сосновые (Pinus sylvestris L.) и лиственнично-сосновые (Larix sibirica Ledeb.) травяно-брусничные леса. 
Исследования проводятся по широкой комплексной программе с применением ландшафтногеохимических методов [28; 38]. Сбор полевых материалов в зимний и летний периоды проводился на экспериментальных площадках ландшафтно-геохимического профиля длиною 31 км. Он расположен по направлению основного массопереноса загрязняющих веществ (CB) и пересекает территорию санитарной зоны БрАЗа, г. Братска, поселков Падун, Энергетик и Гидростроитель. В качестве индикатора была выбрана широко распространенная здесь вечнозеленая и чувствительная к загрязнению сосна обыкновенная. В качестве модельных деревьев использовали молодые (13-18 летние) особи. В конце лета - начале осени описывали жизненное состояние деревьев и наблюдаемые изменения хвои (некроз, хлороз, степень отмирания), измеряли ее длину и толщину, а также линейный прирост ствола, верхушечных и боковых побегов. Параллельно, основываясь на методе листовой диагностики, отбирали хвою предыдущих лет для количественного химического анализа (КХА). В зимний период на опытных площадках ландшафтно-геохимического профиля, а при необходимости и на более обширной территории отбирали снег пластиковым цилиндром в 3-5-кратной повторности с целью выявления элементовзагрязнителей и расчета их нагрузок в растворимой и малорастворимой форме.

Количественный химический анализ массы твердого малорастворимого и растворимого в снеговой воде вещества, накопившегося за зимний период, а также золы хвои сосны выполнялся в сертифицированном Химико-аналитическом центре Института географии им. В.Б. Сочавы СО РАН. Для определения 20 элементов ( $\mathrm{Si}, \mathrm{Al}, \mathrm{Fe}, \mathrm{Ca}, \mathrm{Mg}, \mathrm{K}, \mathrm{Na}, \mathrm{Ti}, \mathrm{Mn}, \mathrm{P}, \mathrm{F}, \mathrm{Sr}, \mathrm{Ba}, \mathrm{Zn}, \mathrm{Cu}, \mathrm{Ni}, \mathrm{Cr}, \mathrm{Co}, \mathrm{Pb}, \mathrm{V}$ ) использовали соответствующие методики $[17 ; 18]$ и спектрометр атомно-эмиссионный с индуктивно связанной плазмой Optima 2000 DV фирмы Perkin Elmer (США). Содержание фтора выявлялось методом прямой потенциометрии на иономере «Эксперт-001» с помощью фторселективного электрода ЭЛИС 131F [19]. Для оценки изменения уровней содержания отдельных элементов в хвое сосны под воздействием поллютантов применялся коэффициент концентрации $(K c=C a / C \phi)$ и коэффициент рассеяния $(K r=C \phi / C a)$, где $C a$ и $C \phi$ - соответственно концентрации элемента в объектах зоны загрязнения (техногенной аномалии) и фона [20]. Для расчета общего количества веществ или отдельных химических элементов, поступающих в природную среду через атмосферу за зимний период, использовали количество талой воды с площади пробоотбора и количество вещества в 1 дм $^{3}$ снеговой воды по формуле: $\mathrm{P}=\mathrm{CV} / \mathrm{S}$, где $\mathrm{P}$ - поступление вещества (малорастворимого, растворимого, отдельных химических элементов) за зимний период, мг $/ \mathrm{m}^{2} ; \mathrm{C}$ - содержание вещества в снеговой воде, мг/дм ${ }^{3} ; \mathrm{V}-$ объем снеговой воды с площади отбора пробы снега, дм ${ }^{3} ; S=\pi R^{2} n-$ площадь пробоотбора (основание пластикового цилиндра), м², n - повторности отбора проб. Годовые нагрузки рассчитывались умножением суточных нагрузок на число дней в году с учетом направления ветров. Статистическая обработка результатов количественного химического анализа проведена по [7].

\section{Результаты и их обсуждение}

На исследуемой территории основными поставщиками загрязняющих веществ считаются такие предприятия, как БрАЗ, ТЭЦ-6, ОАО «Иркутскэнерго», ОАО «Группа “Илим”, на долю которых приходится валовых выбросов в атмосферный воздух 70,3, 15,2 и 3,4\% соответственно. Участие остальных 90 предприятий, в том числе Братского завода ферросплавов, котельных и других более мелких, оценивается суммарно в 8,2\%. Газообразная составляющая представлена преимущественно фтористым водородом (HF), сернистым газом $\left(\mathrm{SO}_{2}\right)$, метилмеркаптаном, твердая - смесью угольной массы, обогащенной окисью алюминия и фторидами, а также зольными элементами [6]. Загрязнение воздушной среды указанными предприятиями нанесло существенный урон лесному фонду вследствие поражения в той или иной степени древесных пород на площади около 200000 га. Из них на площади 4000 га полностью уничтожен древостой. Наряду с этим на большей территории (16000 га) поражен верхний ярус хвойных пород, за исключением отдельных усыхающих деревьев,и угнетен их подрост [24].

Реакция растений на экстремальное воздействие пылегазовых эмиссий. В конце 90-х гг. ХХ в. на БрАЗе была проведена модернизация производства алюминия, с намерением улучшения экологической ситуации и снижения социальной напряженности в г. Братске. В дальнейшем результат проведенных на заводе мероприятий по снижению выбросов в атмосферу пылегазовых веществ был обесценен вследствие повышения выпуска алюминия (свыше миллиона тонн в год), что обусловило усиление хронического воздействия поллютантов на окружающую среду, а также увеличение частоты аварийных выбросов. При этом количество выбрасываемых отходов в виде твердых частиц и газа 
настолько велико, что пыль в это время сплошным слоем устилает земную поверхность, оседает на листьях угнетенных деревьев кустарниковой формы (рис. 1, a) и изреженном травяном покрове. Газообразные вещества, прежде всего, поражают ювенильные особи хвойных пород деревьев открытых местообитаний, а также заросли низкорослых берез, осин и ивовых кустов (рис. 1).
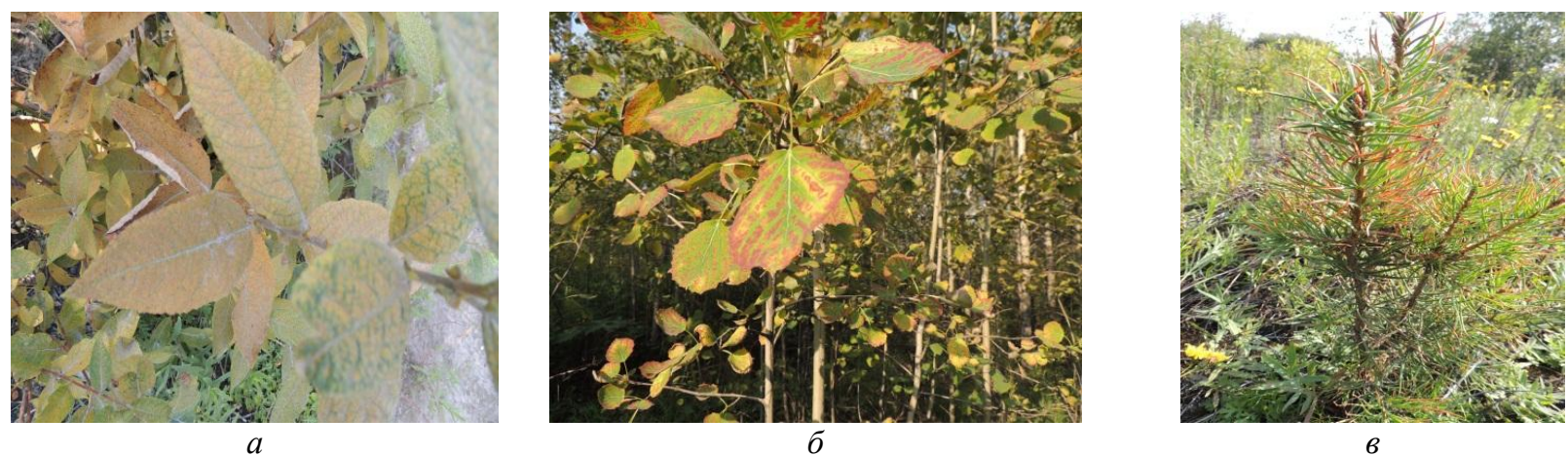

Рис. 1. Жизненное состояние растений вблизи БрАЗа: $a$ - запыление листьев ивы козьей (Salix caprea L.) и их газовое поражение (хлороз, некроз); 6 - газовое поражение листьев угнетенных осин (Populus tremula L.); 6 - многовершинность, хлороз и некроз хвои молодого подроста сосны обыкновенной (Pinus silvestris L.)

Fig. 1. Vital state of plants near BrAZ (Bratsk Aluminium Smelter): $a$-dusting of goat willow leaves (Salix caprea L.) and their gas damage (chlorosis, necrosis); 6 - gas damage of oppressed aspens leaves (Populus tremula L.); 6 - multi-top, needle chlorosis and necrosis in young undergrowth of Scots pine (Pinus silvestris L.)

Реакция сосны обыкновенной на нагрузки поллютантов во времени. Рассчитанные нагрузки поллютантов по содержанию в снежном покрове вблизи завода показывают непостоянство их величин во времени (рис. 2, а, б). В зависимости от количества привнесенных веществ меняются и уровни содержания элементов в хвое сосны обыкновенной (рис. 2, в, г). Об их накоплении или рассеянии по отношению к фоновым концентрациям сосны дает представление диапазон величин коэффициентов $\mathrm{K}_{\mathrm{c}}$ и $\mathrm{K}_{\mathrm{r}}$. Наиболее приемлемы результаты сравнения уровней содержания элементов в хвое сосны зоны загрязнения с ее аналогами районов чистого фона Назаровской котловины [3], Южной Карелии [23], Хакасии [10], нежели с усредненными значениями для всех видов растений [14]. Полученные ряды накопления элементов в хвое сосны по сравнению с их фоновыми значениями для разных районов различны $\left(\mathrm{K}_{\mathrm{c}}-\mathrm{F}_{102-134} \mathrm{Al}_{5-9} \mathrm{Ni}_{5-7} \mathrm{Ti}_{2,4-4,8} \mathrm{Si}_{1,3-4,5} \mathrm{Na}_{2,5-3,3} \mathrm{Sr}_{1,7-3,0} \mathrm{Fe}_{1,4-2,3} \mathrm{Ba}_{1,4-1,9} \mathrm{Ca}_{1,3-1,7} \mathrm{Cr}_{1,1-1,7} \mathrm{Cu}_{1,4-1,6} \mathrm{Zn}_{1,3-1,6}\right)$, также как и ряды рассеяния $\left(\mathrm{K}_{\mathrm{r}}-\mathrm{K}^{1,6-2,6} \mathrm{Mn}^{1,2-2,5} \mathrm{P}^{1,3-2,4} \mathrm{~Pb}^{1,3-2,2} \mathrm{Mg}^{1,2-1,6}\right)$, имея общую тенденцию группировки элементов по величине коэффициентов.

Наибольшими коэффициентами концентрации в хвое (от 7 до 100) выделяется ассоциация элементов $\mathrm{F}, \mathrm{Al}, \mathrm{Ni}$, которые определены как приоритетные загрязнители. Однако только по величине $\mathrm{K}_{\mathrm{c}}$ трудно судить о взаимоотношении растений со средой в условиях загрязнения. Интересные результаты получены при анализе отношения сосны к нагрузкам поллютантов, которые меняются во времени (см. рис. 2). Установлено, что в отношении поглощения элементов сосна проявляет резистентность. Одни элементы она активно поглощает, потребление других заторможено. К первой группе относятся элементы избыточного содержания в среде обитания (F, Al, Na), у которых корреляция содержания с нагрузками характеризуется как положительная очень высокая (табл. 1). В данном случае, как приоритетный элемент выявляется и $\mathrm{Na}$, который при расчете Кс относился к группе второстепенных загрязнителей. Это объясняется его поступлением преимущественно в растворимой форме в результате использования на заводе для выплавки алюминия криолита $\left(\mathrm{Na}_{3} \mathrm{AlF}_{6}\right)$ и фторида натрия $(\mathrm{NaF})$. Они хорошо растворимы в воде, поэтому натрий в природной среде находится в подвижной легко доступной для растений форме. В меньшей степени на уровне средних значений поглощение сосной проявляется у $\mathrm{Ni}, \mathrm{Cr}$ и $\mathrm{Pb}$. Прямая положительная высокая зависимость от нагрузок отмечается также у группы металлов, в том числе щелочноземельных. Напротив, поглощение группы биофильных элементов, таких как $\mathrm{P}, \mathrm{Mg}, \mathrm{K}, \mathrm{Mn}$, физиологически необходимых для развития растений в нормальных природных условиях, заторможено, о чем свидетельствуют средние и низкие отрицательные или несущественные и средние положительные значения коэффициентов корреляции (см. табл. 1). Отмечается также усиленное поглощение кремния, необходимого для наращивания древесины и ее прочности. 

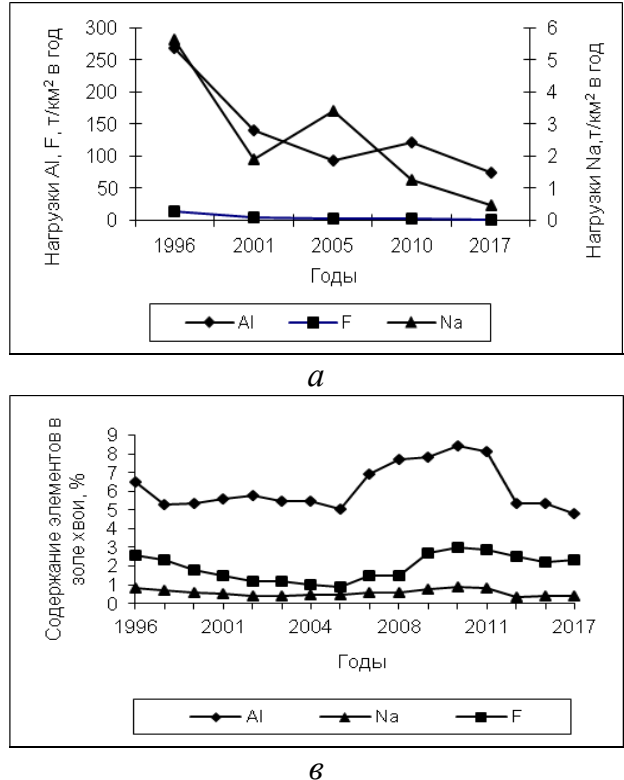
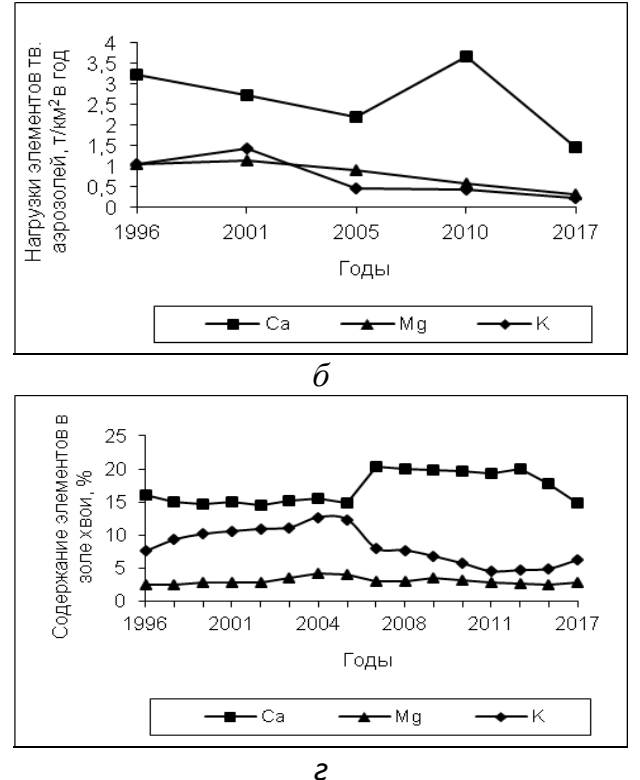

Рис. 2. Нагрузки химических элементов $(a$, б) и их содержание в хвое сосны обыкновенной $(b, 2)$ вблизи БрАЗа Fig. 2. Loads of chemical elements $(a, \sigma)$ and their content in Scots pine conifers $(b, 2)$ near BrAZ

Таблица 1

Коэффициенты корреляци между содержанием элементов в хвое сосны обыкновенной и их нагрузками во времени (20 лет), поступающих в составе твердых аэрозолей вблизи завода

Coefficients of correlation between the content of elements in Scots pine conifers and their loads over time (20 years) coming as part of solid aerosols near the plant

\begin{tabular}{|c|c|c|c|c|c|c|c|c|c|}
\hline Элемент хвои сосньг & \multicolumn{9}{|c|}{ Элемент нагруок } \\
\hline & $\mathrm{Si}$ & $\mathrm{Al}$ & $\mathrm{Ca}$ & $\mathrm{Mg}$ & $\mathrm{K}$ & $\mathrm{Na}$ & $\mathrm{Fe}$ & $\mathrm{Ti}$ & $\mathrm{Mn}$ \\
\hline $\mathrm{Si}$ & 0,86 & - & - & - & - & - & - & - & - \\
\hline $\mathrm{Al}$ & - & 0,97 & - & - & - & - & - & - & - \\
\hline $\mathrm{Ca}$ & - & - & 0,84 & - & - & - & - & - & - \\
\hline $\mathrm{Mg}$ & - & - & - & $-0,36$ & - & - & - & - & - \\
\hline $\mathrm{K}$ & - & - & - & - & 0,23 & - & - & - & - \\
\hline $\mathrm{Na}$ & - & - & - & - & - & 0,91 & - & - & - \\
\hline $\mathrm{Fe}$ & - & - & - & - & - & - & 078 & - & - \\
\hline $\mathrm{Ti}$ & - & - & - & - & - & - & - & 0,70 & - \\
\hline $\mathrm{Mn}$ & - & - & - & - & - & - & - & - & 0,65 \\
\hline $\mathrm{P}$ & $-0,68$ & - & - & - & - & - & - & - & - \\
\hline $\mathrm{F}$ & - & 0,98 & - & - & - & - & - & - & - \\
\hline $\mathrm{Sr}$ & - & - & 0,83 & - & - & - & - & - & - \\
\hline $\mathrm{Ba}$ & - & - & - & 0,71 & - & - & - & - & - \\
\hline $\mathrm{Cr}$ & - & - & - & - & 0,60 & - & - & - & - \\
\hline $\mathrm{Zn}$ & - & - & - & - & - & 0,82 & - & - & - \\
\hline $\mathrm{Ni}$ & - & - & - & - & - & - & 0,51 & - & - \\
\hline $\mathrm{Cu}$ & - & - & - & - & - & - & - & 0,70 & - \\
\hline $\mathrm{Pb}$ & - & - & - & - & - & - & - & - & 0,56 \\
\hline
\end{tabular}

Причина снижения поглощения вблизи завода сосной биофильных элементов связана с присутствием высоких концентраций главного элемента-загрязнителя фторид-иона ( $\left.\mathrm{F}^{-}\right)$, о чем свидетельствуют соответствующие этому положению отрицательные и низкие значения их коэффициентов корреляции (табл. 2). Напротив, отмечено усиленное поглощение сосной Са. Известно, что жизненное состояний растений зависит от их способности переводить токсичные элементы, находящиеся в тканях, в нерастворимые формы, которые не могут участвовать в физиологических процессах $[13 ; 16]$. С этих позиций очень важно присутствие в тканях элементов с высокой осаждающей способностью, каким и является кальций. Его соединение $\mathrm{CaF}_{2}$ - наиболее малорастворимая соль 
$\left(16\right.$ мг/дм $\left.{ }^{3}\right)$ по сравнению с другими солями фтора [2]. В результате этого со временем в сосне накапливаются оба элемента, что подтверждается высоким коэффициентом корреляции и повышенным содержанием кальция. Другая важная особенность физиологических процессов растений - поглощение калия, образующего с поллютантами хорошо растворимые соединения, которые нейтрализуют токсиканты и легко выводят их из организмов [12]. Это видно на примере сосны, в хвое которой вероятен процесс обезвреживания фтора калием путем образования фторида калия (KF), что подтверждается отрицательной величиной коэффициента парной корреляции, свидетельствующего о процессе вымывания калия из хвои сосны (см. табл. 2) и нахождении его в ассоциации рассеивающихся элементов. Вероятно, в какой-то мере эту функцию выполняет натрий, находящийся в легко доступной форме $\left(\mathrm{F}^{-}-\right.$ $\mathrm{Na}^{+}$) в снеговой воде (до $30 \mathrm{мг} /$ дм$^{3}$ ) и почвенных растворах (более $20 \mathrm{Mг} /$ дм$^{3}$ ). Следует также отметить проявление слабой поглотительной способности у сосны не только относительно $\mathrm{P}, \mathrm{Mg}, \mathrm{K}, \mathrm{Mn}$, но и $\mathrm{Zn}$, $\mathrm{Cu}, \mathrm{Pb}$, что объясняется опосредованным влиянием фтора через кальций, который усиленно поглощается сосной. Подобное явление наблюдалось в условиях повышенного содержания техногенного кальция в почвах (соответственно и в растениях) вблизи Назаровской ТЭЦ, работающей на бурых углях [4].

Таблица 2

Корреляция между содержанием фтора и содержанием других элементов в хвое сосны обыкновенной

вблизи завода (в течение 20 лет)

Correlation between the content of fluoride and other elements in Scots pine needles near the plant (for 20 years)

\begin{tabular}{|c|c|c|c|c|c|c|c|c|}
\hline \multicolumn{9}{|c|}{ Коэффициент корреляии } \\
\hline Элемент & $\mathrm{Si}$ & $\mathrm{Al}$ & $\mathrm{Ca}$ & $\mathrm{Mg}$ & $\mathrm{K}$ & $\mathrm{Na}$ & $\mathrm{Fe}$ & $\mathrm{Ti}$ \\
\hline $\mathrm{F}$ & 0,37 & 0,43 & 0,70 & $-0,59$ & $-0,69$ & 0,62 & 0,60 & 0,64 \\
\hline Элемент & $\mathrm{Mn}$ & $\mathrm{P}$ & $\mathrm{Sr}$ & $\mathrm{Ba}$ & $\mathrm{Zn}$ & $\mathrm{Ni}$ & $\mathrm{Cu}$ & $\mathrm{Pb}$ \\
\hline $\mathrm{F}$ & 0,30 & $-0,80$ & 0,57 & 0,55 & 0,22 & 0,66 & 0,36 & 0,77 \\
\hline
\end{tabular}

Способность сосны обыкновенной изменять химический состав хвои адекватно меняющимся нагрузкам поллютантов повысило вероятность определения во времени снижения или повышения экологического риска, связанного с динамикой выбросов в атмосферу массы твердых и газообразных фторидов. Выделены следующие периоды: 1 - высокая степень риска до модернизации производства (1967-1996 гг.), 2 - снижение степени риска после модернизации (1997-2005 гг.), 3 - повышение степени риска при увеличении выпуска алюминия (2006-2010 гг.), 4 - высокая степень риска - выпуск алюминия на уровне более 1 млн т в год (2011-2017 гг.). В этот период участились залповые выбросы в атмосферу загрязняющих веществ.

\section{Реакция сосны обыкновенной на содержания химических элементов твердых аэрозолей}

Установлено, что уровни их содержания в аэрозолях непостоянны в пространстве. Повышенным содержанием выделяется отмеченная ранее группа элементов, состоящая из трех членов (F, Al, Ni), приуроченная к территории БрАЗа (рис. $3, a, 6$ ). С удалением от него содержание указанных элементов снижается и, напротив, других элементов, в том числе Na, увеличивается. На общем фоне повышенным загрязнением выделяются г. Братск (6 км от завода), поселки: Падун (20 км), Энергетик (25), Гидростроитель (30) (рис. 3). Поставщиком металлов ( $\mathrm{Fe}, \mathrm{Zn}, \mathrm{Pb}, \mathrm{Ti}, \mathrm{Cu}, \mathrm{Cr}$ ) являются Братский завод ферросплавов и автотранспорт, группы щелочноземельных элементов (Ca, $\mathrm{Mg}, \mathrm{Sr}, \mathrm{Ba})$, a также $\mathrm{K}$ и $\mathrm{P}$ ТЭЦ-6, ТЭЦ-7, котельные, трубы печного отопления. Натрий привносится в результате применения $\mathrm{NaCl}$ как реагента против образования наледей на дорогах, а также его добычи, перевозки и использования в виде сырья при получении хлора предприятием ОАО «Группа “Илим”» (рис. 3).

Присутствие указанных элементов в воздухе и почвах сказывается и на элементном составе хвои сосны (рис. 3, в, г). О тесноте связи между содержанием химических элементов в твердых аэрозолях и хвое сосны можно судить на основании величин коэффициентов корреляции (табл. 3), которые для большинства элементов находятся в диапазоне высоких положительных значений. Отрицательная связь для Са свидетельствует об отсутствии необходимости в его усиленном поглощении с удалением от главного источника эмиссий фторидов. 

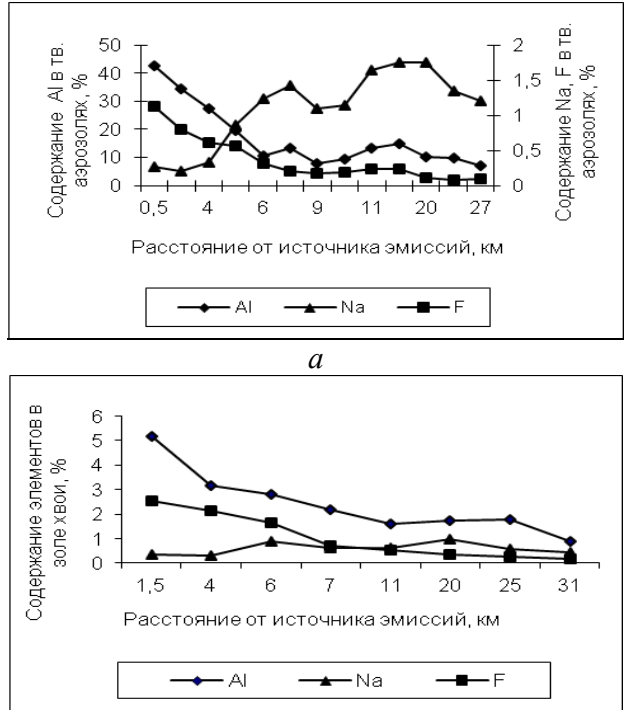
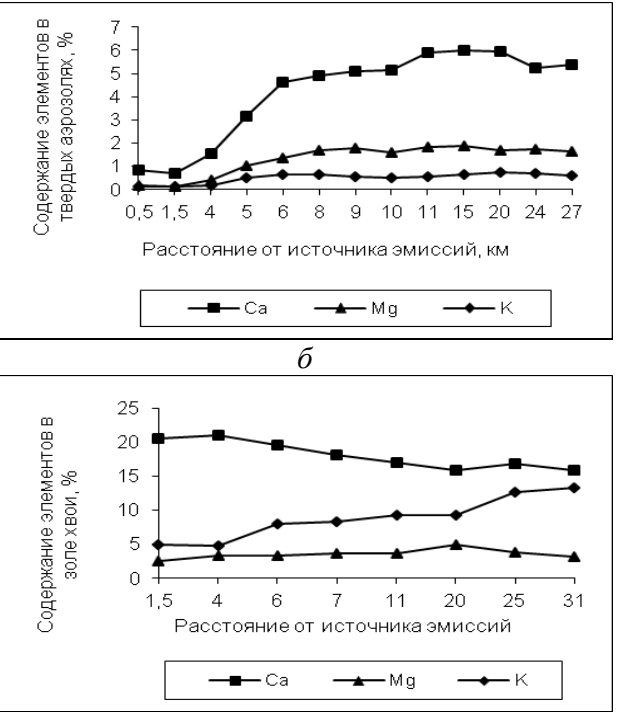

Рис. 3 Содержание элементов-загрязнителей в твердых аэрозолях $(a, 6)$ и содержание элементов в хвое сосны обыкновенной ( 6 , г) с удалением от завода к северо-востоку

Fig. 3 Content of polluting agents in solid aerosols $(a, \sigma)$ and content of elements in Scots pine needles $(b, 2)$ with a distance away from the plant in a north-eastern direction

Таблица 3

Корреляция между содержанием элементов в твердых аэрозолях и хвое сосны обыкновенной с удалением от завода к северо-востоку

Correlation between the content of elements in solid aerosols and Scots pine needles with a distance away from the plant in a north-eastern direction

\begin{tabular}{|c|c|c|c|c|c|c|c|c|c|}
\hline Элементы хвои & \multicolumn{9}{|c|}{ Элементы твердых аэрозолей } \\
\hline- & $\mathrm{Si}$ & $\mathrm{Al}$ & $\mathrm{Ca}$ & $\mathrm{Mg}$ & $\mathrm{K}$ & $\mathrm{Na}$ & $\mathrm{Fe}$ & $\mathrm{Ti}$ & $\mathrm{Mn}$ \\
\hline $\mathrm{Si}$ & 0,77 & - & - & - & - & - & - & - & - \\
\hline $\mathrm{Al}$ & - & 0,96 & - & - & - & - & - & - & - \\
\hline $\mathrm{Ca}$ & - & - & -94 & - & - & - & - & - & - \\
\hline $\mathrm{Mg}$ & - & - & - & 0,72 & - & - & - & - & - \\
\hline $\mathrm{K}$ & - & - & - & - & 0,71 & - & - & - & - \\
\hline $\mathrm{Na}$ & - & - & - & - & - & 0,72 & - & - & - \\
\hline $\mathrm{Fe}$ & - & - & - & - & - & - & 0,64 & - & - \\
\hline $\mathrm{Ti}$ & - & - & - & - & - & - & - & 0,78 & - \\
\hline Mn & - & - & - & - & - & - & - & - & $-0,49$ \\
\hline элемент & $\mathrm{P}$ & $\mathrm{F}$ & $\mathrm{Sr}$ & $\mathrm{Ba}$ & $\mathrm{Cr}$ & $\mathrm{Zn}$ & $\mathrm{Ni}$ & $\mathrm{Cu}$ & $\mathrm{Pb}$ \\
\hline $\mathrm{P}$ & 0,56 & - & - & - & - & - & - & - & - \\
\hline $\mathrm{F}$ & - & 0,99 & - & - & - & - & - & - & - \\
\hline $\mathrm{Sr}$ & - & - & 0,96 & - & - & - & - & - & - \\
\hline $\mathrm{Ba}$ & - & - & - & 0,72 & - & - & - & - & - \\
\hline $\mathrm{Cr}$ & - & - & - & - & 0,51 & - & - & - & - \\
\hline $\mathrm{Zn}$ & - & - & - & - & - & 0,78 & - & - & - \\
\hline $\mathrm{Ni}$ & - & - & - & - & - & - & 0,80 & - & - \\
\hline $\mathrm{Cu}$ & - & - & - & - & - & - & - & 0,33 & - \\
\hline $\mathrm{Pb}$ & - & - & - & - & - & - & - & - & 0,85 \\
\hline
\end{tabular}


Парный корреляционный анализ содержания фттора и других элементов в хвое сосен подтверждает наличие высокого уровня прямой положительной связи $\mathrm{F}$ с Al и $\mathrm{Ni}$, содержание которых с удалением от БрАЗа однозначно уменьшается, и, напротив, отрицательную связь фтора с элементами, поступающими дополнительно от других источников (табл. 4). Корреляция элемента-загрязнителя с кальцием и в данном случае остается высокой $(\mathrm{r}=0,96)$, т.е. с уменьшением фтора снижается и поглощение сосной кальция, что еще раз указывает на особенную роль этого элемента в нейтрализации токсического действия фтора для обеспечения устойчивости сосны в условиях высокой степени атмосферного загрязнения.

В неспецифических условиях существования на процесс поглощения элементов растениями влияют как различия в механизмах поглощения и доступность элементов, так и в физиологических процессах, включающих их обмен, синергизм и антагонизм [12, 15, 37].

Таблица 4

Корреляция между содержанием фтора и содержанием других элементов в хвое сосны обыкновенной с удалением от завода к северо-востоку

Correlation between the contents of fluoride and other elements in Scots pine needles with a distance away from the plant in a north-eastern direction

\begin{tabular}{|c|c|c|c|c|c|c|c|c|}
\hline \multicolumn{9}{|c|}{ Коэффициент коррелячи } \\
\hline Элемент & $\mathrm{Si}$ & $\mathrm{Al}$ & $\mathrm{Fe}$ & $\mathrm{Mg}$ & $\mathrm{Ca}$ & $\mathrm{K}$ & $\mathrm{Na}$ & $\mathrm{Ti}$ \\
\hline $\mathrm{F}$ & -46 & 0,91 & -50 & $-0,63$ & 0,96 & $-0,89$ & $-0,50$ & $-0,78$ \\
\hline & $\mathrm{Mn}$ & $\mathrm{P}$ & $\mathrm{Sr}$ & $\mathrm{Ba}$ & $\mathrm{Zn}$ & $\mathrm{Ni}$ & $\mathrm{Cu}$ & $\mathrm{Pb}$ \\
\hline $\mathrm{F}$ & 0,19 & $-0,85$ & $-0,95$ & 0,09 & $-0,72$ & 0,83 & $-0,38$ & 0,52 \\
\hline
\end{tabular}

\section{Выводы}

В результате многолетних натурных исследований в зоне техногенного воздействия на компоненты таежных геосистем пылегазовых эмиссий крупного завода по производству алюминия были выявлены особенности взаимодействия широко распространенной здесь сосны обыкновенной с потоками поллютантов, что позволяет ей выживать в изменяющихся условиях геохимической среды обитания в отличие от других хвойных пород деревьев. Установлено избирательное поглощение элементов (в первую очередь кальция), способных переводить избыточное содержание токсикантов в нерастворимую малоактивную форму, что снижает их токсичность, а также поглощение щелочных элементов, предпочтительно калия, но в определенных условиях, и натрия способных нейтрализовать кислотные компоненты и переводить их в растворимые легко вымываемые соединения из растения. Кроме этого, отмечаются увеличение плотности и толщины кутикулы хвои и способность сосны располагать верхний разветвленный ярус корневой системы ниже сильно загрязненного слоя почвы.

Несмотря на все сложности взаимоотношений сосны со средой при поглощении химических элементов, а также процессов метаболизма, синергизма и антагонизма в самом растении, установлена ее адекватная реакция на нагрузки поллютантов. Прямая положительная связь между нагрузками приоритетных элементов-загрязнителей, повышенным их содержанием в хвое сосны и сниженным линейным приростом ствола и веток является хорошим диагностическим признаком реакции сосны на загрязнение, что позволяет применять ее в качестве индикатора, а также использовать при нормировании нагрузок поллютантов.

Благодарности. Исследование выполнено за счет средств государственного задания (№ госрегистраиии темы АAAA-A17-117041910171, АAAA-A21-121012190055-7).

Acknowledgments. The study was funded as part of a state assignment (topic state registration No. AAAA-A17-117041910171, AAAA-A21-121012190055-7).

\section{Библиографический список}

1. Биоиндикация загрязнений наземных экосистем. М.: Мир, 1988. 348 с.

2. Большая таблица растворимости. [Электронный ресурс]. URL: https://chemiday.com/ru/table-solubility (дата обращения: 29.06.2019).

3. Волкова В.Г., Давыдова Н.Д. Содержание химических элементов в растениях в зоне техногенного воздействия // География и природные ресурсы. Новосибирск, 1984. № 3. С. 75-81.

4. Волкова В.Г., Давыдова Н.Д. Техногенез и трансформация ландшафтов // Новосибирск: Наука, 1987. 189 с. 
Физическая география, ландшафтоведение и геоморфология

Давыдова Н.Д.

5. Глазовская М.А. Геохимия природных и техногенных ландшафтов СССР. М.: Высшая школа, 1988. 328 с.

6. Государственный доклад «О состоянии окружающей природной среды Иркутской области». Иркутск: Издво Госком. Экологии РФ и Адм. обл, 1993-2008 гг.

7. Губин В.И., Осташков В.Н. Статистические методы обработки экспериментальных данных: учеб. пособие для студентов технических вузов. Тюмень: Изд-во Тюм. ГНГУ, 2007. 202 с.

8. Гудериан Р. Загрязнение воздушной среды. М.: Мир, 1979. 200 с.

9. Давыдова Н.Д. Трансформация геохимической среды в техногенной аномалии // Проблемы биогеохимии и геохимической экологии. Семипалатинск, 2012. №3(20). С. 72-81.

10. Давыдова Н.Д., Знаменская Т.И. Техногенное вещество в степных ландшафтах. Новосибирск, Академическое издательство "Гео", 2018. 147 с. doi:10.21782/B978-5-6041445-3-4.

11. Давыдова Н.Д. Мониторинг природной среды регионов Сибири по загрязнению снежного покрова // Фундаментальные исследования. 2015. №8 (ч.3). С. 469-475.

12. Илькун Г.М. Загрязнители атмосферы и растения. Киев: Наукова думка, 1978. 245 с.

13. Кулагин Ю.З. Газоустойчивость древесных растений и накопление серы в их листьях // Растительность и промышленные загрязнения. Свердловск: Наука, 1970. С. 36-41.

14. Малюга Д.П. Биогеохимический метод поисков рудных месторождений. М.: Изд.-во АН СССР, 1963. 264 с.

15. Мэннинг У. Дж., Федер У.А. Биомониторинг загрязнения атмосферы с помощью растений. Л., 1985. 142 с.

16. Павлов И.Н. Изучение сорбции фтора в листьях древесных растений // Химия растительного сырья. 1998. № 2. C. 37-43.

17. ПНДФ 16.1:2.3:3-11-98. Методика выполнения измерений содержания металлов в твердых объектах методом атомно-эмиссионной спектрометрии с индуктивно-связанной плазмой. М., 2005.28 с.

18. ПНДФ 14.1:2:4.135-2005. Методика выполнения измерений массовой концентрации элементов в пробах питьевой, природных, сточных вод и атмосферных осадков атомно-эмиссионной спектрометрии с индуктивносвязанной плазмой. М., 2008. 24 с.

19. РД 52.24.360-2008. Массовая концентрация фторидов в водах: методика выполнения измерений потенциометрическим методом с ионселективным электродом. Ростов н/Д., 2008, 25 с.

20. Сает Ю.Е., Смирнова Р.С. Геохимические принципы выявления зон воздействия промышленных выбросов в городских агломерациях // Вопросы географии. М.: Мысль, 1983. Сб. 120. С. 45-55.

21. Сает Ю.Е., Ревич Б.А., Янин Е.П. и др. Геохимия окружающей среды. М.: Недра, 1990. 335 с.

22. Техногенные потоки вещества в ландшафтах и состояние экосистем. М.: Наука, 1981. 252 с.

23. Уфимцева М.Д., Терехина Н.В. Фитоиндикация экологического состояния урбогеосистем СанктПетербурга. СПб: Наука, 2005. 339 с.

24. Чжан С.A. Лесоводственная оценка состояния сосновых насаждений в условиях длительного техногенного загрязнения: автореф. докт. дис. с/х наук (06.03.02). Красноярск, 2014. 31 c.

25. Bharti V.K., Giri A., Kumar K. Fluoride Sources, toxicity and its amelioration: Reviw. Reviw. Sci Toxicol, 2017. 2(1): 021-032. doi: 10.17352/aest. 000009.

26. Bhat N., Jain S.,Asawa K., Tak M., Shinde K., Singh A., Gandhi N.,Gupta V.V. Concentration of soil and vegetables in vicinity of zinc smelter, Debari, Udaipur Rajasthan. J Clin Diagn Res. 2015. 9(10): ZC63-ZC66.

27. Dässler H.-G., Ranft H., Rehn K.-H. Zur Widerstansfahigkeit von Geholzen gegenüber Fluorverbindungen und Schwefeldioxid // Flora. 1972. Bd.161, №3. S.298-302.

28. Glazovskaya M.A. Geochemical Basis of the Typology and Methods of Natural Landscape Research. 2 Edition. Smolensk, Moscow, Oikumena, 2002. 288 p.

29. James L. Shupe, Miner M.L., Greenwood D.A. Clinical and pathological aspects of fluorine toxicosis in cattle // Annals of the New York Academy of Sciences. 1964. Vol. 111. Veterinary Toxicologypages. P. 618-637.

30. Kabata-Pendias A. Trace elements in soil and plants. 4-th edition. CRC Press, Taylor \& Francis Group, 2011. 505 p.

31. Kasimov N.S. Ecogeochemistry of Landscapes. Moscov: IP Filimonov M.V. (eds) (in Russian). 2013. 208 p.

32. Koshelewa N.S., Kasimov N.S., Vlasov D.V. Factors of the accumulation of heavy metals and metalloids at geochemical darries in urban soils // Eurasian Soil Science. 2015. Vol. 48, № 5. P. 476-492.

33. Leone I.A., Brennan E., Daines R.H. Atmospheric Fluoride: Its Uptake and Distribution in Tomato and Corn Plants // Plant Physiol. 1956. Vol.31. P. 329-333.

34. Linde M., Oborn I., Gustafsson J.P. Effects of changed soil conditions on the mobility of trace metals in moderately contaminated urban soils // Water, Air and Soil Pollnion. 2007. V.183. P. 69-83.

35. Liu Y., Chen L., Zhao J., Wei Y., Pan Z., Meng X.-Z., Huang Q., Li W. Polycyclic aromatic hydrocarbons in the surface soil of Shanghai, China: concentrations, distribution and sources // Organic Geochemistry. 2010. V. 41. P. 355-362.

36. Mauer H. Waldbau und immisionsschaden // “Osterr. Forstztg”, 1987. № 12. S.22-23.

37. Pavlov I.N. Formation of fluorine technogenic anomalies in above-ground ecosystems of Siberia: biological sorption, monitoring, possibility of lowering the negative impact // Contemporary Problems of Ecology. 2014. T.7, №3. C. 353-362.

38. Perelman A.I., Kasimov N.S. Landscape Geochemistry. Moscow, Astreya, 2000, 1999. 763 p. 
Физическая география, ландшафтоведение и геоморфология

Давыдова Н.Д.

\section{References}

1. Shubert, R. (ed.) (1988), Bioindikatsiya zagryaznenii nazemnykh ehkosistem. World, Moscow, Russia.

2. Large solubility table. Electronic resource available at: https://chemiday.com/ru/table-solubility (Accessed 29 June 2019).

3. Volkova, V.G., Davydova, N.D. (1984), "Soderzhaniye khimicheskikh elementov v rasteniyakh v zone tekhnogennogo vozdeystviya" Geografiya i prirodnyye resursy, Novosibirsk, Russia, no. 3, pp. 75-81.

4. Volkova, V.G., Davydova, N.D. (1987), Tekhnogenez i transformatsiya landshaftov, Sib's Science publishing house, Novosibirsk, Russia.

5. Glazovskaya, M.A. (1988), Geokhimiya prirodnykh i tekhnogennykh landshaftov SSSR [Geochemistry of natural and technogenic landscapes of the USSR], Moscow, Vysshaya shkola Publ., 1988, 328p.

6. Gosudarstvennyy doklad (1993-2008), «O sostoyanii okruzhayushchey prirodnoy sredy Irkutskoy oblasti». Irkutsk: Goskom. Ekol. RF i Adm. obl.

7. Gubin, V.I., Ostashkov, V.N. (2007), Statisticheskie metody obrabotki ehksperimental'nykh dannykh. Uchebnoe posobie dlya studentov tekhnicheskikh vuzov, Tyumen, TYuM. GNSU Publ., 202 p.

8. Guderian, R. (1979), Zagryaznenie vozdushnoi sredy [Air pollution], Moscow, World Publ., 200 p.

9. Davydova, N.D. (2012), Transformatsiya geokhimicheskoy sredy v tekhnogennoy anomalii [Transformation of the geochemical environment into a technogenic anomaly], Problemy biogeokhimii i geokhimicheskoy ekologii [Problems of biogeochemistry and geochemical ecology]. Kazakhstan, Semipalatinsk, no. 3(20), pp. 72-81.

10. Davydova, N.D., Znamenskaya, T.I. (2018), Tekhnogennoe veshchestvo v stepnykh landshaftakh [Man-made matter in steppe landscapes]. Novosibirsk: Geo Publ. doi: 10.21782/B978-5-6041445-3-4.

11. Davydova, N.D. (2015), Monitoring prirodnoy sredy regionov Sibiri po zagryazneniyu snezhnogo pokrova [Monitoring of the natural environment of Siberian regions for pollution of snow cover] Fundamentalnyye issledovaniya [Basic research], no 8 (part 3), pp. 469-475.

12. Ilkun, G.M. (1978), Zagryazniteli atmosfery` $\mathrm{i}$ rasteniya [Air pollutants and plants], Kiev, Naukova Dumka Publ.

13. Kulagin, Yu.Z. (1970), Gazoustojchivost` drevesny`x rastenij i nakoplenie sery` v ix list`yax [Gas resistance of woody plants and the accumulation of sulfur in their leaves], Rastitel'nost` $i$ promy`shlenny`e zagryazneniya [Vegetation and industrial pollution], Sverdlovsk, Nauka, pp. 36-41.

14. Malyuga, D.P. (1963), Biogeokhimicheskii metod poiskov rudnykh mestorozhdenii [Biogeochemical method of prospecting for ore deposits], Moscow, Publishing house of the USSR Academy of Sciences.

15. Mehnning, U. Dzh., Feder, U.A. (1985), Biomonitoring zagryazneniya atmosfery s pomoshch'yu rastenii [Biomonitoring air pollution using plants] L., $142 \mathrm{p}$.

16. Pavlov, I.N. (1998), Izuchenie sorbtsii ftora v list'yakh drevesnykh rastenii [Study of the sorption of fluorine in the leaves of woody plants], Chemistry of plant raw materials [Chemistry of plant raw materials], no. 2, pp. 37-43.

17. PNDF 16.1: 2.3: 3-11-98 (2005), Metodika vypolneniya izmereniy soderzhaniya metallov v tverdykh ob"yektakh metodom atomno-emissionnoy spektrometrii s induktivno-svyazannoy plazmoy [Methods for measuring metal content in solid objects by inductively coupled plasma atomic emission spectrometry] Moscow, 28 p.

18. PNDF 14.1:2:4.135-2005 (2008), Metodika vypolneniya izmereniy massovoy kontsentratsii elementov v probakh pit'yevoy, prirodnykh, stochnykh vod i atmosfernykh osadkov atomno-emissionnoy spektrometrii s induktivno-svyazannoy plazmoy [Methods for measuring the mass concentration of elements in samples of drinking, natural, waste water and atmospheric precipitation by atomic emission spectrometry with inductively coupled plasma] Moscow, $24 \mathrm{p}$.

19. RD 52.24.360-2008 (2008), Massovaya kontsentratsiya ftoridov v vodakh: metodika vypolneniya izmereniy potentsiometricheskim metodom s ionselektivnym elektrodom [Mass concentration of fluorides in waters: a technique for performing measurements by the potentiometric method with an ion-selective electrode]. Rostov-on-Don, 25p.

20. Saet, Yu. E., Smirnova, R. S. (1983), Geochemical principles of identification of zones of impact of industrial emissions in urban agglomerations. Questions of geography. Moscow: Mysl, s.120, p. 45-55.

21. Saet, Yu. E., Revich, B.A., Yanin, E.P. (1990), Geokhimiya okruzhayushchey sredy [Geochemistry of the environment], Nedra, Moscow, Russia.

22. Tekhnogennye potoki veshchestva $v$ landshaftakh i sostoyanie ehkosistem (1981), Science, $252 \mathrm{p}$.

23. Ufimtseva, M.D., Terekhina, N.V. (2005), Fitoindikatsiya ehkologicheskogo sostoyaniya urbogeosistem SanktPeterburga, Science, St. Petersburg, Moscow, Russia.

24. Zhang, S. A. (2014), Forest management assessment of pine plantations in conditions of long-term technogenic pollution, Abstract of the Doct. Diss. of agricultural Sciences (06.03.02). Krasnoyarsk, 31 p. (in Russian).

25. Bharti, V.K., Giri, A., Kumar, K. (2017), Fluoride Sources, toxicity and its amelioration: Reviw. Reviw. Sci Toxicol, vol. 2, no. 1. doi: 10.17352/aest. 000009.

26. Bhat, N., Jain, S.,Asawa, K., Tak, M., Shinde, K., Singh, A., Gandhi, N.,Gupta, V.V. (2015), Concentration of soil and vegetables in vicinity of zinc smelter, Debari, Udaipur Rajasthan. J Clin Diagn Res, 9(10): ZC63-ZC66.

27. Dässler, H.-G., Ranft, H., Rehn, K.-H. (1972), Zur Widerstansfahigkeit von Geholzen gegenüber Fluorverbindungen und Schwefeldioxid // Flora, vol. 161, no. 3, pp. 298-302. 
28. Glazovskaya, M.A. (2002), Geochemical Basis of the Typology and Methods of Natural Landscape Research, 2 Edition, Smolensk, Moscow, Oikumena.

29. James, L. Shupe, Miner, M.L., Greenwood, D.A. (1964), "Clinical and pathological aspects of fluorine toxicosis in cattle", Annals of the New York Academy of Sciences, Veterinary Toxicologypages, vol. 111, pp. 618-637.

30. Kabata-Pendias, A. (2011), Trace elements in soil and plants. 4-th edition. CRC Press, Taylor \& Francis Group.

31. Kasimov, N.S. (2013), Ecogeochemistry of Landscapes. IP Filimonov M.V. (eds), Moscow, Russia.

32. Koshelewa, N.S., Kasimov, N.S., Vlasov, D.V. (2015), "Factors of the accumulation of heavy metals and metalloids at geochemical darries in urban soils", Eurasian Soil Science, vol. 48, no. 5, pp. 476-492.

33. Leone, I.A., Brennan, E., Daines, R.H. (1956), “Atmospheric Fluoride: Its Uptake and Distribution in Tomato and Corn Plants", Plant Physiol, vol. 31, pp. 329-333.

34. Linde, M., Oborn, I., Gustafsson, J.P. (2007), "Effects of changed soil conditions on the mobility of trace metals in moderately contaminated urban soils", Water, Air and Soil Pollnion, vol. 183, pp. 69-83.

35. Liu, Y., Chen, L., Zhao, J., Wei, Y., Pan, Z., Meng, X.-Z., Huang, Q., Li, W. (2010), "Polycyclic aromatic hydrocarbons in the surface soil of Shanghai, China: concentrations, distribution and sources", Organic Geochemistry, vol. 41, pp. 355-362.

36. Mauer, H. (1987), "Waldbau und immisionsschaden”, Osterr. Forstztg, no. 12, pp. $22-23$.

37. Pavlov, I.N. (2014), "Formation of fluorine technogenic anomalies in above-ground ecosystems of Siberia: biological sorption, monitoring, possibility of lowering the negative impact", Contemporary Problems of Ecology, vol. 7, no. 3, pp. 353-362.

38. Perel`man, A.I., Kasimov, N.S. (1999), Landscape Geochemistry, Publ. H. Astreya-2000, Moscow, Russia.

Поступила в редакцию: 20.11.2020.

\section{Сведения об авторе}

\section{Нина Даниловна Давыдова}

доктор географических наук, ведущий

научный сотрудник, профессор Российской Академии

Естествознания. Институт географии им. В. Б. Сочавы

COPAH;

Россия, 664033, Иркутск, Улан-Баторская, 1.

e-mail: davydova@irigs.irk.ru

\author{
About the author \\ Nina D. Davydova \\ Doctor of Geographical Sciences, Leading Researcher, \\ Professor at the Russian Academy of Natural Sciences \\ V. B. Sochava Institute of Geography of the Siberian Branch \\ of the Russian Academy of Sciences; \\ 1, Ulan-Batorskaya st., Irkutsk, 664033, Russia.
}

Просьба ссылаться на эту статью в русскоязычных источниках следующим образом:

Давыдова Н.Д. Реакция сосны обыкновенной на неумеренные выбросы в атмосферу загрязняющих веществ // Географический вестник = Geographical bulletin. 2021. №1(56). С. 31-41 doi 10.17072/2079-7877-2021-1-31-41.

Please cite this article in English as:

Davydova N.D. (2021) Response of Scots pine to increased emissions of pollutants into the atmosphere. Geographical Bulletin. No. 1(56). Pp. 31-41. doi 10.17072/2079-7877-2021-1-31-41. 